Norma Fimbres Durazo*

\title{
EMIGRACIÓN, INMIGRACIÓN Y RETORNO: EL CICLO DE LOS INMIGRANTES MEXICANOS EN CALÉXICO, CALIFORNIA, EUA
}

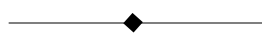

\section{RESU MEN}

En esteartículo se describea una comunidad de inmigrantes mexicanos residentes legales en la ciudad deCaléxico, California. En primer término, sereseña brevemente la historia dela migración deM éxico a Estados Unidos, en particular al condado de Imperial. En segundo, se describen las características del grupo de inmigrantes a partir de los datos provenientes de una encuesta aplicada a 407 inmigrantes mexicanos. Para finalizar, se presentan los resultados que proporciona la encuesta sobre las causas que intervinieron en la emigración, los motivos para inmigrar y la relación que existe entreel inmigrantey su país deorigen, a través dela migración deretorno.

\section{A BSTRACT}

This article describes a community of Mexican immigrants legally residing in the city of Calexico, California. Firstly, a brief review on the history of migration from M exico to the United States, chiefly to Imperial County, is presented. Afterwards, the traits of the immigrant group is described according to the data coming from a survey that was applied to 407 Mexican immigrants. To conclude, the results provided by the survey on the causes for such emigration, the motives for immigrating, as well as the bearing existing between the immigrant and his/ her country of origin, through the return migration, are all presented.

\footnotetext{
* InVEStigadora del instituto de InVEStigaciones sociales de la uABC. Correo electrónico: nfimbres@faro.ens.uabc.mx
} 


\section{INTRODUCCIÓN}

El presentetrabajo describea unacomunidad deinmigrantesmexicanos residentes legales en la ciudad de Caléxico, localizada en el condado deImperial, ubicado al sur de California, Estados Unidos, contiguo a la ciudad de Mexicali, Baja California, México.

Socialmente, el proceso migratorio ha generado dos tipos de migrantes: el de los legales, que corresponde a los inmigrantes que, mediante el otorgamiento de documentos oficiales por parte de las autoridades estadounidenses, pueden ingresar a Estados Unidos para residir y trabajar; y el de los indocumentados, que corresponde a los inmigrantes que entran al país sin documentos. Esta diferencia en el estatus mi gratorio de entrada a Estados Unidos caracteriza no sól o el proceso migratorio, sino también al inmigranteen cuanto a la percepción delo quees el proceso y su integración a la sociedad receptora.

El trabajo se desarrolla en tres partes. La primera esuna brevereseña histórica dela migración demexicanos a Estados Unidos en general , y al condado delmperial en particular, con el fin deubicar a la población objeto de estudio, ya que la situación actual no puede ser entendida fuera de su contexto histórico. La segunda parte describe las características del grupo deinmigrantes a partir de los datos provenientes de una encuesta aplicada en 1995 a 407 inmigrantes que cubrieron las siguientes características: tener 18 años de edad o más, ser mexicanos y no haber obtenido la ciudadanía estadounidense. En el tercer punto sepresentan los resultados queproporciona la encuesta sobrelas causas que intervinieron en la emigración y los motivos por los cuales inmigraron ehicieron de esta local idad su asentamiento permanente. Por último, se presenta la relación que existe entre el inmigrante y su país de origen, a través de la migración de retorno.

Los movimientos migratorios internacionales no son nuevos, y en el transcurso del tiempo han adquirido características diferentes, por lo que ya no se pueden considerar solamente como movimiento de población, sino más bien como movimiento defuerza detrabajo (Alba, 1986:356). Deahí que, a medida quetranscurree tiempo, la discusión en torno al movimiento depersonas entrefronteras - como en el caso dela migración entre México y Estados Unidos- refleja nuevasfacetas 
queleimprimen características particulares al proceso, puessi bien es un movimiento deindividuos económicamenteproductivos quetiene carácter internacional, también es un movimiento de personas que portan el ementos socioculturales que, junto con ellos, trascienden las fronteras.

Otro elemento presenteen el movimiento migratorio es la dirección de las migraciones, que se considera como el desplazamiento de la fuerza de trabajo de países subdesarrollados a países desarrollados, y el migrantees considerado sólo como el portador dela fuerza detrabajo dentro del mercado de la oferta y la demanda. Por ello, es necesario incorporar al análisis del proceso otros elementos que forman parte del inmigrante como individuo, aun cuando la decisión de migrar es una decisión personal.

\section{ANTECEDENTESHISTÓRICOSDE LA MIGRACIÓN MÉXICO-ESTADOSUNIDOS}

La migración de mexicanos a Estados Unidos dio inicio a mediados del siglo pasado, cuando el antiguo territorio septentrional deM éxico se perdió como consecuencia del expansionismo estadounidense en los años de 1836 a 1853. A partir de ese tiempo, y por condiciones históricas de cada uno de los países, ha habido grandes periodos de emigración de México a Estados Unidos, intensificándose ésta en los últimos años del porfiriato, cuando el régimen político entró en crisis debido a queel sector agrícola mostraba poco dinamismo y generaba una escasa producción de al imentos, y el mercado laboral era incapaz de absorber la fuerza de trabajo en proporción al ritmo de su crecimiento. En esa época, el desarrollo del país fue impulsado por la inversión extranjera en la explotación de los recursos naturales, y en la infraestructura de los ferrocarriles, que fue lo que vinculó de forma importante a México con el norte del país y con los Estados Unidos (Alba, 1986:356).

Durante los años de 1880 a 1910, Estados Unidos generó un rápido crecimiento económico, integrando a este proceso de la economía nacional al suroeste del país, lo que propició una demanda continua demano de obra. En aquel tiempo, la frontera era físicamenteinexistentey los mexicanos no encontraban obstáculos para ingresar al país 
(López Castro, 1986:568). La agricultura y la minería tuvieron un gran auge en el suroeste de EUA, y ambas actividades generaron una demanda de mano de obra que no podía ser satisfecha con los trabajadores estadounidenses del suroeste, pues había muy poca población, y debido precisamentea ello y a la cantidad detrabajadores en la región y al número de personas desempleadas en México, la migración fue inevitable y acelerada por las nuevas vías de comunicación (Massey, et al., 1991:51), entrelas queel ferrocarril tuvo unaindiscutiblepreponderancia.

Estados Unidos y México se interconectaron en 1884 a través del Southern Pacific Rail Iroad y el Ferrocarril Mexicano Internacional, alos que posteriormenteseanexaron otras vías, de modo que para 1890, las líneas mexicanas del ferrocarril se unían directamentea 48 estados del vecino país del norte (Massey, et al., 1991:53).

Otro de los periodos que propició la internacional ización de mano de obra mexicana que proveniente del centro de México se dirigió a Estados Unidos, fueel estallamiento dela revolución mexicana de1910. En esetiempo y durantelas luchas posteriores, la emigración aumentó notablemente debido a la violencia e inseguridad económica y social que generó la revolución. Sin embargo, a finales de los años veinte, Estados Unidos sufrió una de las crisis económicas más fuertes de su historia conocida como la gran depresión de 1929, que produjo un estancamiento y detenimiento dela corrientemigratoria debido a que el gobierno, con ayuda de las autoridades de los estados, puso en marcha el proceso de expulsión de miles de inmigrantes mexicanos legal es eindocumentados.

Ya para 1930 en M éxico, los resultados dela revolución empezaban a mostrar algunos signos positivos en la estructura socioeconómica, sobre todo en el sector agrícola, aunque fue hasta 1940 cuando se pusieron en práctica las medidas de reforma formuladas a la Constitución de 1917, y que fueron establecidas durante el periodo presidencial de Lázaro Cárdenas (1934-1940), mismas que incluían la redistribución de tierra laborable y la ubicación de los campesinos expulsados de Estados Unidos en algunos centros ejidales.

A raíz de la segunda guerra mundial y de la participación deEUA en la contienda, seoriginó un gran cambio en la actitud delos habitantes 
estadounidenses hacia el inmigrante mexicano: el clima de xenofobia quehabía acompañado a las deportaciones masivas demexicanos años atrás, fue sustituido por una nueva imagen de los mexicanos como hard w orking people. El ingreso delosEstados Unidosa la segunda guerra mundial en 1942, marcó una nueva etapa en la demanda de mano de obra mexicana, a partir dela iniciativa propuesta por el Departamento deDefensa del gobierno estadounidense, dondesol icitaban al gobierno de México que aportara mano de obra para la causa de los aliados, ya que la fuerza de trabajo local se había convertido en ejército y la producción agrícola del suroeste corría el riesgo de perderse (Bustamante y Martínez, 1980:16). Como resultado de esta iniciativa se firmó un acuerdo entre ambos gobiernos, mediante el cual trabajadores mexicanos podían ingresar a los Estados Unidos con la finalidad desuplir a losobreros estadounidenses. Fueasí como en 1942 inició el Programa Bracero, queEstados Unidos dio por terminado en 1964. Al finalizar dicho programa, los gobiernos de ambos países dejaron departicipar en la contratación y regularización detrabajadores migrantes; no obstante, con o sin políticas oficiales, la migración legal e ilegal de mexicanos a los Estados Unidos ha seguido en aumento.

\section{LA INMIGRACIÓN MEXICANA EN EL CONDADO DE IMPERIAL}

La expansión del capitalismo estadounidensedefinales del siglo pasado se caracterizó por la centralización y concentración de capitales, que generaron la apertura de nuevos espacios de crecimiento y desarrollo en distintos puntos del suroeste de la unión americana, como en el caso del Valle Imperial, hoy condado, donde la inversión de capital propició el desarrollo de la región y generó una gran oleada de migrantes de Arizona, del norte de Cal ifornia, y de otros estados del este como Pennsylvania e Illinois. Los inmigrantes Ilegaron como pioneros a colonizar el Valle Imperial -ya quea finales del siglo XIX seencontraba prácticamentedespoblado-, gracias a la promoción que hicieron las compañías encargadas del desarrollo delaregión, las cuales ofrecían a los inmigrantes la posi bilidad deobtener tierras para cultivo.

A pesar deser una zona desértica, árida y escasa de precipitaciones pluviales, la región del Valle Imperial contaba con un gran atractivo: Ia 
fertilidad de sus suelos y las pendientes naturales que caracterizan a dicha depresión, que hicieron posible derivar por gravedad las aguas del Río Colorado y que posibilitaron la agricultura de la región. La presentación y ejecución del proyecto para introducir las aguas del Río Colorado al Vallelmperial estuvo a cargo dela CaliforniaDevelopment Co. (Compañía para el Desarrollo de California), creada en 1896. Paralelamente, en 1900 se creó la agencia colonizadora Imperial Land Co. (Compañía de Tierras de Imperial), con el propósito de ubicar poblados y parcelar la tierra. Con ello, para el año de 1905 en el Valle Imperial, ya se habían planificado y ubicado los poblados del mperial, Caléxico, Dixieland, Brawley, El Centro y Holtville(Estrella, 1982:8).

El poblado deCaléxico, pertenecienteal condado delmperial, surgió en 1901 debido a que la Compañía para el Desarrollo de California estableció sus oficinas central es cerca dela frontera internacional entre California y el entonces Distrito N orte de Baja California. A partir de esemomento, y para 1903, lo queera el área del pueblo de Caléxico fue dividida y lotificada, surgiendo así lo que es el actual asentamiento urbano. El área agrícola que está alrededor de la ciudad forma parte del Valle Imperial, y fuela primera porción del valleen ser irrigada y mejorada para el cultivo (Estrella, 1982:11).

El inicio del desarrollo capitalista en el Vallelmperial ocasionó que un gran contingente demexicanos inmigrara a la región: había trabajo, existía una gran necesidad de mano de obra, y el país vecino se encontraba con problemas sociales, políticos y económicos que favorecían la emigración. Esta corriente de inmigrantes llegó de diferentes lugares dela república mexicana, y partedeella seincorporó a las labores agrícolas del Valle Imperial. A partir deentonces y hasta nuestros días, la inmigración de mexicanos en la ciudad de Caléxico ha sido constante, lo que ha ocasionado que algunos inmigrantes mexicanos se establezcan como residentes permanentes en esa localidad.

En el mismo periodo en que surgió la actual ciudad de Caléxico se fundó el asentamiento de Mexicali. Con el paso del tiempo, Mexicali creció a un ritmo más acel erado quesu gemela del lado estadounidense; sin embargo, ambas aumentaron su población como consecuencia de las corrientes migratorias provenientes del interior del país. La adopción 
del régimen de zona libre en la porción norte del estado de Baja Cal ifornia, como al ternativa para garantizar el abasto de la población mexicana radicada en la franja fronteriza así como su asentamiento permanente, condujo a que las ciudades del sur de Estados Unidos, sobre todo aquellas ubicadas contiguas a la línea fronteriza, se convirtieran en abastecedoras de mercancías, bienes de consumo y servicios dela población fronteriza del lad o mexicano. Caléxico no fue la excepción; todavía a mediados de la década de los setenta era el principal centro de abasto de los mexicalenses.

Así, Caléxico, deser una región fundamental menteagrícola, añadió a su economía las actividades comercialesy, con ello, se estableció una relación deinterdependencia económica entrelas dos ciudades.

Por su parte, para los migrantes mexicanos, la ciudad de Mexicali se convirtió en el lugar de llegada y punto de salida hacia el país del norte, de tal manera que en 1990, según el censo de población de los Estados Unidos, la población del condado de Imperial era de 109300 habitantes, de los cuales $65.2 \%$ era de origen hispano, mientras queen la ciudad de Caléxico el total de la población ascendía a 18633 habitantes, de los cuales $95.6 \%$ era deesemismo origen. La distribución dela población en las local idades del condado de Imperial se observa en el cuadro 1, donde uno de los dos asentamientos que registran los porcentajes más altos de población de origen hispano es la ciudad de Caléxico, sólo superada por Heber, con 96.8\%.

Si bien la ciudad de Caléxico registra un porcentaje de $95.6 \%$ de población hispana, en él están incluidos inmigrantes no sólo de ascendencia mexicana, sino también de otros países latinoamericanos, cuya representatividad es muy baja. Deacuerdo con el censo de 1990, en el total de la población hispana se incluyen 47 personas de origen no mexicano (8 puertorriqueños, 17 cubanos, 11 colombianos y 11 peruanos).

\section{CARACTERÍSTICASSOCIODEMOGRÁFICASDE LA POBLACIÓN ESTUDIADA}

A partir de los datos provenientes de la muestra de 407 personas, se observa quela población en general esjoven, con un promedio deedad de 43.5 años, sin diferencias significativas en la media de edad de 
CuADRO 1. Población total y porcentaje de hispanos del Condado de Imperial, 1990.

\begin{tabular}{|l|r|r|c|}
\hline Ciudad & $\begin{array}{c}\text { Población } \\
\text { total }\end{array}$ & $\begin{array}{c}\text { Población } \\
\text { hispana }\end{array}$ & $\begin{array}{c}\text { Porcentaje } \\
\text { pob. hispana }\end{array}$ \\
\hline Condado deImperial & 109300 & 72500 & $65.2 \%$ \\
Brawley & 18923 & 13076 & $69.1 \%$ \\
Caléxico & 18633 & 17806 & $95.6 \%$ \\
Calipatria & 2690 & 1995 & $74.2 \%$ \\
El Centro & 31384 & 20482 & $65.3 \%$ \\
Heber & 2566 & 2485 & $96.8 \%$ \\
Holtville & 4820 & 3011 & $62.5 \%$ \\
Imperial & 4113 & 2176 & $52.9 \%$ \\
Niland & 1183 & 427 & $36.1 \%$ \\
Seeley & 1228 & 847 & $69.0 \%$ \\
Westmorland & 1380 & 997 & $72.2 \%$ \\
\hline
\end{tabular}

Fuente: U.S., Bureau of the Census. Census of Population, 1990.

hombres y mujeres. Del total dela muestra, $42.5 \%$ correspondeal sexo masculino y $57 \%$ al femenino (ver cuadro 2). En conjunto, $42 \%$ registra una edad entre los 18y 39 años, con un predominio del grupo delos 40 a 49 años de edad (26.8\%), y una mayor distribución relativa de los hombres en los grupos de 18 a 29 y de 60 y más años de edad.

Como se mencionó, $95.6 \%$ de la población de Caléxico es hispana (ver cuadro 1), lo que representa 17806 habitantes, delos cuales $99.7 \%$ es de origen mexicano; es decir, 95.3\% de los residentes en Cal éxico son mexicanos o descendientes de éstos.

\section{LUGAR DE ORIGEN}

En cuanto al lugar de nacimiento, se destaca la importancia de la población proveniente de Baja California, pues del conjunto de los inmigrantes legales mexicanos en la localidad $46.7 \%$ de los entrevistados nació en Baja California (ver cuadro 3). 
CUADRO 2. Mexicanos residentes legales en Caléxico. Composición dela muestra según edad y sexo.

\begin{tabular}{|l|r|c|c|r|r|r|}
\hline \multirow{2}{*}{ Grupo deedad } & \multicolumn{2}{|c|}{ Hombres } & \multicolumn{3}{c|}{ Mujeres } & \multicolumn{2}{c|}{ Total } \\
\cline { 2 - 8 } & A bs. & $\%$ & Abs. & $\%$ & Abs. & $\%$ \\
\hline 18 a 29 & 40 & 23.2 & 42 & 17.9 & 82 & 20.2 \\
30 a 39 & 32 & 18.6 & 57 & 24.4 & 89 & 21.9 \\
40 a 49 & 39 & 22.7 & 70 & 29.9 & 109 & 26.8 \\
50 a 59 & 21 & 12.2 & 33 & 14.1 & 54 & 13.3 \\
60 y más & 40 & 23.3 & 32 & 13.7 & 72 & 17.7 \\
No especificado & 1 & & & & 1 & \\
Total & 173 & 100.0 & 234 & 100.0 & 407 & 100.0 \\
\hline
\end{tabular}

FuENTE: Encuesta del proyecto “Mexicanos residentes legales en Caléxico, Ca.", IIS-SDSU, 1995.

CuAdRo 3. Mexicanos residentes legales en Caléxico, según entidad federativa denacimiento y sexo.*

\begin{tabular}{|l|rr|r|r|rr|}
\hline \multirow{2}{*}{$\begin{array}{l}\text { Estado de } \\
\text { nacimiento }\end{array}$} & \multicolumn{2}{|c|}{ Hombres } & \multicolumn{2}{c|}{ Mujeres } & \multicolumn{2}{c|}{ Total } \\
\cline { 2 - 7 } & Abs. & $\%$ & Abs. & $\%$ & Abs. & $\%$ \\
\hline \multirow{2}{*}{ BajaCalifornia } & 78 & 45.2 & 112 & 47.9 & 190 & 46.7 \\
Jalisco & 18 & 10.4 & 20 & 8.5 & 38 & 9.3 \\
Michoacán & 13 & 7.5 & 10 & 4.3 & 23 & 5.7 \\
Sinaloa & 12 & 6.9 & 30 & 12.8 & 42 & 10.3 \\
Sonora & 16 & 9.2 & 16 & 6.8 & 32 & 7.9 \\
Otrosestados & 36 & 20.8 & 46 & 19.7 & 82 & 20.1 \\
Total & 173 & 100.0 & 234 & 100.0 & 407 & 100.0 \\
\hline
\end{tabular}

FUENTE: Encuesta del proyecto “Mexicanos residentes legales en Caléxico, Ca.", IIS-SDSU, 1995.

* Los resultados de la prueba $x^{2}$ no fueron significativos, por lo tanto la composición de la muestra según sexos es independiente del lugar de origen. 
Otro aspecto a señalar es que las entidades federativas mexicanas que se ubican en la costa del Pacífico — desde Michoacán hasta Baja California — aportan al rededor de $80 \%$ de los inmigrantes legales en Caléxico (ver figura 1). Es importante señal ar que estos estados mexicanos son los mismos que, en el municipio de Mexicali en particular y en Baja California en general, aportan los mayores porcentajes de su población no nativa.

En el caso del municipio de Mexicali, deacuerdo con la información del censo de población de 1990, las cinco entidades federativas mencionadas en el cuadro 3 representan los lugares de origen de aproximadamente 86\% dela población municipal (INEGI, 1990:7-8). El $20 \%$ restante dela muestra corresponde a otros estados, y secompone delas personas nacidas en 13 entidades federativas mexicanas.

El estatus de residente legal y el tiempo de residencia de los inmigrantes en la ciudad deCaléxico, son variables quepueden mostrar el grado de asimilación quetieneel inmigrante en el país. El cuadro 4 presenta el tiempo deresidencia delos inmigrantes por grupos deaños de residencia y lugar denacimiento, y en él se observa quela mayoría de los inmigrantes tiene seis o más años de residencia, lo que en conjunto representa cerca de $80 \%$ del total de la muestra.

CUADRO 4. Tiempo de residir en Caléxico según lugar de nacimiento (porcentajes).

\begin{tabular}{|l|r|r|r|r|r|r|}
\hline $\begin{array}{l}\text { Tiem./resid. } \\
\text { lug./nac. }\end{array}$ & B. C. & Jalisco & Michoacán & Sinaloa & Sonora & $\begin{array}{c}\text { Total } \\
\text { muestra }\end{array}$ \\
\hline 1-5 años & 23.4 & 15.8 & 18.2 & 16.7 & 25.8 & 21.3 \\
6-10años & 29.8 & 18.4 & 36.4 & 11.9 & 16.1 & 23.1 \\
11-15años & 9.6 & 21.1 & 13.6 & 7.1 & 12.9 & 11.9 \\
16-20años & 16.0 & 21.1 & 22.7 & 16.7 & 19.4 & 17.1 \\
21-25años & 7.4 & 7.9 & - & 21.4 & 6.5 & 9.4 \\
26añosy más & 13.8 & 15.8 & 9.1 & 26.2 & 19.4 & 17.1 \\
Total & 100.0 & 100.0 & 100.0 & 100.0 & 100.0 & 100.0 \\
Media & 13.95 & 14.92 & 12.5 & 18.76 & 17.13 & 15.53 \\
Error est. & .83 & 1.42 & 1.91 & 1.67 & 2.92 & .58 \\
Desv. est. & 11.32 & 8.75 & 8.97 & 10.82 & 16.26 & 10.91 \\
Núm. casos & 188 & 38 & 22 & 42 & 31 & 403 \\
\hline
\end{tabular}

Fuente: Encuesta del proyecto “Mexicanos residentes legal es en Caléxico, Ca.", IIS-SDSU, 1995. 


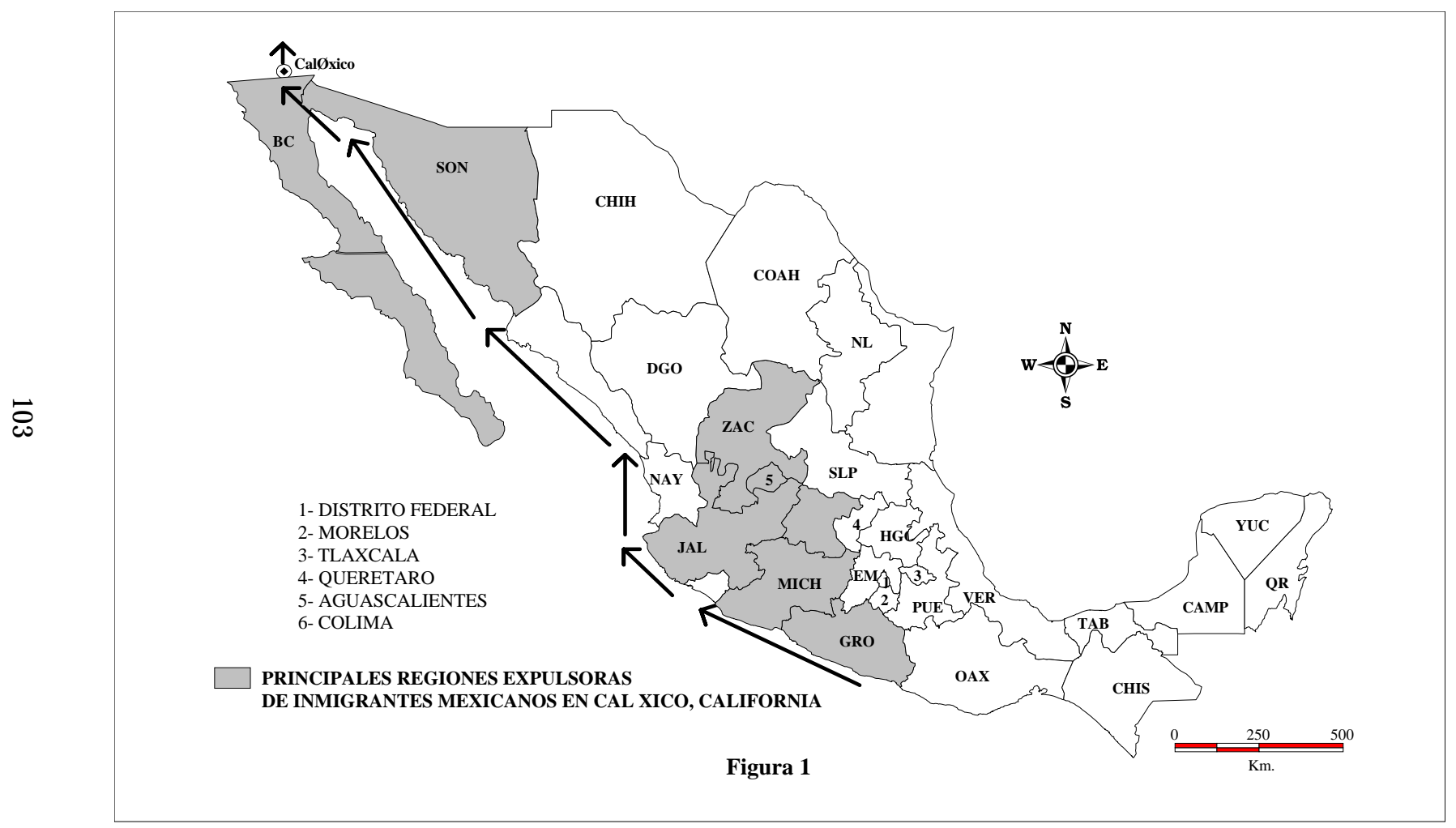


Lo quellama la atención del grupo de inmigrantes, es que aquéllos quetienen seis años o más de residencia (98.7\%) cuentan con el tiempo suficiente como para haber gestionado su ciudadanía. Esto permite advertir que no sólo es el requisito de tiempo de residencia lo que influye en la obtención de la ciudadanía, sino queel inmigrante tiene otros motivos para no realizar el trámite denacionalización.

Del total delos entrevistados, $86.7 \%$ dedararon queno han solicitado la ciudadanía por diferentes razones (ver cuadro 5); de ese porcentaje 19.4\% respondió queno tienen interés en hacer el trámite, lo quepuede deberse en gran parte a que los inmigrantes residentes legales aún conservan los mismos apoyos y derechos quelos ciudadanos, situación quetal vez influya en la indiferencia de los inmigrantes en solicitar la ciudadanía.

Por otra parte, un obstáculo para solicitar la ciudadanía es el idioma, pues $12.3 \%$ respondió queno han solicitado la ciudadanía por no saber inglés. Por otrolado, mucho seha dicho quelosinmigrantes mexicanos no optan por la ciudadanía estadounidense porque tienen muy arraigado el sentimiento de su nacionalidad, aunque la información proporcionada por los entrevistados indica que este motivo no tiene gran peso, ya que sólo 1.0\% de ellos respondió no haber solicitado la ciudadanía por patriotismo. El resto delas respuestas son muy variadas, los motivos argumentados van desde: "no he podido" (14.0\%), "después lo voy a hacer" (10\%), "no he tenido tiempo" (10\%), "no necesito" (6.1\%), "estoy estudiando", "es muy cara”, "estoy muy viejo" (1\%), hasta "por fal ta deorientación para realizar los trámites" (3.2\%). En $15.7 \%$ deno respuesta, está considerado 13.3\% de los entrevistados que en el momento de la entrevista habían solicitado la ciudadanía y estaban esperando una respuesta.

\section{EMIGRACIÓN: CAUSASQUE ORIGINARON SU PARTIDA}

A pesar dequelamigradión demexicanos duranteel presentesiglohatenido un carácter voluntario tanto en losantiguos como en losactual esinmigrantes, uno de los factores más importantes queha provocado la emigradón dela mayoría de los migrantes mexicanos son las diferentes condiciones y estructuras económicas deambos países (García y Griego, et al. 1988:56). 
CUAdRO 5. Motivos por los que los inmigrantes mexicanos residentes legales en Caléxico, California, no han solicitado la ciudadanía.

\begin{tabular}{|c|c|c|c|c|}
\hline Motivos & & $\begin{array}{c}\text { Hombres } \\
\%\end{array}$ & $\begin{array}{c}\text { Mujeres } \\
\%\end{array}$ & $\begin{array}{c}\text { Total } \\
\%\end{array}$ \\
\hline No les interesa & $\begin{array}{l}\mathrm{R} \\
\mathrm{C}\end{array}$ & $\begin{array}{l}49.4 \\
22.5\end{array}$ & $\begin{array}{l}50.6 \\
17.1\end{array}$ & 19.4 \\
\hline No saben inglés & $\begin{array}{l}\mathrm{R} \\
\mathrm{C}\end{array}$ & $\begin{array}{r}24.0 \\
6.9\end{array}$ & $\begin{array}{l}76.0 \\
16.2\end{array}$ & 12.3 \\
\hline Están estudiando & $\begin{array}{l}\mathrm{R} \\
\mathrm{C}\end{array}$ & $\begin{array}{r}57.1 \\
2.3\end{array}$ & $\begin{array}{r}42.9 \\
1.3\end{array}$ & 1.7 \\
\hline Hasta después & $\begin{array}{l}\mathrm{R} \\
\mathrm{C}\end{array}$ & $\begin{array}{l}43.9 \\
10.4\end{array}$ & $\begin{array}{r}56.1 \\
9.8\end{array}$ & 10.1 \\
\hline Muy cara & $\begin{array}{l}\mathrm{R} \\
\mathrm{C}\end{array}$ & $\begin{array}{r}25.0 \\
.6\end{array}$ & $\begin{array}{r}75.0 \\
1.3\end{array}$ & 1.0 \\
\hline Motivos de salud & $\begin{array}{l}\mathrm{R} \\
\mathrm{C}\end{array}$ & & $\begin{array}{r}100.0 \\
.4\end{array}$ & 0.2 \\
\hline No tienen tiempo & $\begin{array}{l}\mathrm{R} \\
\mathrm{C}\end{array}$ & $\begin{array}{l}45.2 \\
11.0\end{array}$ & $\begin{array}{r}54.8 \\
9.8\end{array}$ & 10.3 \\
\hline No la necesitan & $\begin{array}{l}\mathrm{R} \\
\mathrm{C}\end{array}$ & $\begin{array}{r}52.0 \\
7.5\end{array}$ & $\begin{array}{r}48.0 \\
5.1\end{array}$ & 6.1 \\
\hline $\begin{array}{l}\text { Tienen que esperar el } \\
\text { tiempo necesario }\end{array}$ & $\begin{array}{l}\mathrm{R} \\
\mathrm{C}\end{array}$ & $\begin{array}{r}26.7 \\
2.3\end{array}$ & $\begin{array}{r}73.3 \\
4.7\end{array}$ & 3.7 \\
\hline Están muy viejos & $\begin{array}{l}\mathrm{R} \\
\mathrm{C}\end{array}$ & $\begin{array}{r}40.0 \\
1.2\end{array}$ & $\begin{array}{r}60.0 \\
1.3\end{array}$ & 1.2 \\
\hline No pueden tramitarla & $\begin{array}{l}\mathrm{R} \\
\mathrm{C}\end{array}$ & $\begin{array}{l}56.1 \\
18.5\end{array}$ & $\begin{array}{l}43.9 \\
10.7\end{array}$ & 14.0 \\
\hline Falta de orientación & $\begin{array}{l}\mathrm{R} \\
\mathrm{C}\end{array}$ & & $\begin{array}{r}100.0 \\
5.6\end{array}$ & 3.2 \\
\hline Por patriotismo & $\begin{array}{l}\mathrm{R} \\
\mathrm{C}\end{array}$ & $\begin{array}{r}100.0 \\
2.3\end{array}$ & & 1.0 \\
\hline No respondieron & $\begin{array}{l}\mathrm{R} \\
\mathrm{C}\end{array}$ & $\begin{array}{l}39.1 \\
14.5\end{array}$ & $\begin{array}{l}60.9 \\
16.7\end{array}$ & 15.7 \\
\hline Total & & 42.5 & 57.5 & 100.0 \\
\hline
\end{tabular}

Fuente: Encuesta del proyecto “M exicanos residentes legal es en Caléxico, Ca.", IIS-UABC-SDSU, 1995.

$\mathrm{R}=$ Porcentaje de renglón $\mathrm{C}=$ Porcentaje de columna. 
Si bien históricamente la oferta y la demanda de fuerza de trabajo han si do losfactores quehan regulado la migración entreambos países, no se puede dejar de lado otro factor como lo es la difusión masiva de los valores y el estilo de vida estadounidense, que influyen en el inmigranteal tomar la decisión de partir.

En cuanto al grupo de inmigrantes encuestados, los motivos que tuvieron para emigrar fueron los siguientes: $46.7 \%$, por tener mejores condiciones de vida; $42.0 \%$, por reunir a la familia; $5.2 \%$, para tener mejor educación, y 2.5\%, porque arregló sus documentos de inmigración. El 3.7\% no respondieron (ver cuadro 6).

CUADRO 6. Motivos de emigración de los mexicanos residentes legales en Caléxico, California.

\begin{tabular}{|c|c|c|c|c|c|c|}
\hline \multirow[t]{2}{*}{ Motivos } & \multicolumn{2}{|c|}{ Hombres } & \multicolumn{2}{|c|}{ Mujeres } & \multicolumn{2}{|c|}{ Total } \\
\hline & Abs. & $\%$ & Abs. & $\%$ & Abs. & $\%$ \\
\hline Mejor vida & 101 & & 89 & & 190 & 46.7 \\
\hline $\mathrm{R}$ & & 53.2 & & 46.8 & & \\
\hline C & & 58.4 & & 8.0 & & \\
\hline Motivosfamiliares & 52 & & 119 & & 171 & 42.0 \\
\hline $\mathrm{R}$ & & 30.4 & & 69.6 & & \\
\hline C & & 30.1 & & 50.9 & & \\
\hline $\begin{array}{l}\text { Arregló documentos } \\
\text { deinmigración }\end{array}$ & 1 & & 9 & & 10 & 2.5 \\
\hline $\mathrm{R}$ & & 10.0 & & 90.0 & & \\
\hline C & & 0.6 & & 3.8 & & \\
\hline Educación & 10 & & 11 & & 21 & 5.2 \\
\hline $\mathrm{R}$ & & 47.6 & & 52.4 & & \\
\hline C & & 5.8 & & 4.7 & & \\
\hline No respondió & 9 & & 6 & & 15 & 3.7 \\
\hline $\mathrm{R}$ & & 60.0 & & 40.0 & & \\
\hline C & & 5.2 & & 2.6 & & \\
\hline Total & 173 & 42.5 & 234 & 57.5 & 407 & 100.0 \\
\hline
\end{tabular}

Fuente: Encuesta del proyecto “Mexicanos residentes legales en

Caléxico, Ca.", IIS-UABC-SDSU, 1995

$\mathrm{R}=$ porcentaje de renglón. $\mathrm{C}=$ porcentaje de columna. 
A partir de los resultados, es interesante observar que para $58.4 \%$ de los hombres el motivo principal fue el mejorar su nivel de vida, mientras que $38 \%$ de las mujeres contestó queéste fuesu motivo para emigrar. El segundo motivo lo constituyen razones familiares, donde el mayor porcentajecon esta respuesta fue para las mujeres, con 50.9\% del total de ellas, mientras que de los hombres sólo 30.1\% emigra por tal motivo. No es deextrañar quepara los hombres el motivo principal para emigrar sea la búsqueda de mejores condiciones de vida, ya que en ellostradicionalmenteha recaído la responsabilidad de proporcionar sustento a la familia; de igual manera, tampoco es raro que en las mujeres el mayor peso relativo de los motivos para emigrar sean los familiares, puesto queen buena medida, la mujer emigra una vez que el cónyugese ha establecido y está en posibilidad detraer al resto dela familia. Sin embargo, también se observó el caso de mujeres que emigraron para mejorar sus condiciones de vida, lo que hace suponer quesetrata demujeres queson jefes de la familia o, en su defecto, que están dispuestas a apoyar a su pareja en la manutención del hogar.

Si bien el motivo principal para emigrar fuetener mejores condiciones devida, $75.7 \%$ delos entrevistados respondió queen México tenían lo indispensablepara vivir (trabajo, techo, educación), mientras que $23.8 \%$ tomaron la decisión de emigrar porque carecían de lo indispensable para vivir; de ellos, $13.3 \%$ respondió que les faltaba todo. $4.9 \%$ necesitaba trabajo, $4.7 \%$ requería dinero, y $1.5 \%$ no respondió. En este caso en particular sepuedeseñal ar queno son los más pobres deM éxico los que emigran, ya que buena parte de los emigrantes contaban con empleo en su lugar de origen, pero valoran la diferencia salarial que existeentreambos países y que para muchos inmigrantes puedeser el factor más importante, ya queles puedeproporcionar mayor bienestar y acceso a otros bienes, y no sólo lo indispensable para vivir.

Otro factor que influye en los migrantes es la información que se establecea través de las redes sociales, los familiares o paisanos quese encuentran ya establecidos en el extranjero y envían información sobre el lugar, las oportunidades de trabajo que existen y sobrelas maneras deinmigrar (ver cuadro 7). Así, tenemos que 68.6\% delos entrevistados obtuvo información por parte de algún familiar; 10.8\% a través del Consulado de Estados Unidos en México, y 9.3\% de los amigos; estas 
redes sociales de información no sólo se utilizan para enviar información, sino que en gran medida brindan seguridad y facilitan a los nuevos migrantes su integración al lugar de destino (Massey, 1991:319).

Por los resultados, se puede deducir que en más de la mitad delos inmigrantes los motivos quetuvieron para emigrar, seoriginan por la interacción defuerzas económicas de México y EstadosUnidos, donde el primero tiene una mano de obra subempleada, dispuesta a emigrar, y en el segundo, hay una constante demanda de mano de obra. Otro motivo por el cual una persona decideemigrar — no menos fuerteque el primero- es reunir a la familia, lo que logra con el apoyo de las redes sociales deinformación queconstruyeel migrantey que, deuna manera directa, sevinculan al primer motivo, ya queemigran a trabajar o para seguir a un familiar quevino por ese motivo.

\section{INMIGRACIÓN : ASENTAMIENTO E INTEGRACIÓN}

Cada migrantees portador de un bagajecultural que, al Ilegar al lugar de destino, se mezcla con la cultura local y le imprime características particulares al lugar dedestino. Así, la inmigración demexicanos en la ciudad de Caléxico, California, ha hecho de ella el centro urbano de mayor población deorigen mexicano en el suroestedeEstados Unidos (U .S., Census of Population, 1990), lo que que ha traído como consecuencia una hispanización dela ciudad a través dela cultura: es común en la ciudad escuchar el español, quees el idioma quese habla en la mayoría de los hogares, comercios y oficinas (eincluso se acepta la moneda mexicana en casi la totalidad de los establecimientos comerciales), por lo que se puede decir que Caléxico es una ciudad atípica debido a la presencia tan marcada de dos culturas. Lo anterior, sin duda, es para el inmigrante mexicano un factor que facilita la integración y permanencia y quesemanifiesta en el ámbito social y en el desarrollo y crecimiento económico, ya que la fuerza de trabajo del inmigrantemexicano siemprehajugado un papel muy importantetanto en las labores agrícolas del Valle Imperial, como en el comercio y servicios dela ciudad. 
CUADRO 7. Fuentes de información utilizadas por los inmigrantes mexicanos para emigrar.

\begin{tabular}{|c|c|c|c|c|c|c|}
\hline \multirow{2}{*}{$\begin{array}{c}\text { Fuente de } \\
\text { información }\end{array}$} & \multicolumn{2}{|c|}{ Hombres } & \multicolumn{2}{|c|}{ Mujeres } & \multicolumn{2}{|c|}{ Total } \\
\hline & Abs. & $\%$ & Abs. & $\%$ & Abs. & $\%$ \\
\hline Amigos & 21 & & 17 & & 38 & 9.3 \\
\hline $\mathrm{R}$ & & 55.3 & & 44.7 & & \\
\hline $\mathrm{C}$ & & 12.1 & & 7.3 & & \\
\hline Familiares & 106 & & 173 & & 279 & 68.6 \\
\hline $\mathrm{R}$ & & 38.0 & & 62.0 & & \\
\hline C & & 61.3 & & 73.9 & & \\
\hline Consulado deEUA & 22 & & 22 & & 44 & 10.8 \\
\hline $\mathrm{R}$ & & 50.0 & & 50.0 & & \\
\hline C & & 12.7 & & 9.4 & & \\
\hline Otro & 24 & & 21 & & 45 & 11.1 \\
\hline $\mathrm{R}$ & & 53.3 & & 46.7 & & \\
\hline C & & 13.9 & & 9.0 & & \\
\hline No respondió & & & 1 & & 1 & 0.2 \\
\hline $\mathrm{R}$ & & & & 100.0 & & \\
\hline $\mathrm{C}$ & & & & 0.4 & & \\
\hline Total & 173 & 42.5 & 234 & 57.5 & 407 & 100.0 \\
\hline
\end{tabular}

Fuente: Encuesta del proyecto “M exicanos residentes legales en Caléxico, Ca.", IIS-UABC-SDSU, 1995

$\mathrm{R}=$ porcentaje derenglón. $\mathrm{C}=$ porcentaje de columna.

Respecto delos motivos por los cual es los inmigrantes encuestad os optaron por residir permanentementeen esta ciudad, $26.3 \%$ respondió queviveen ella porquees una ciudad fronteriza; $29.7 \%$, por estar cerca del resto dela familia, y 17.9\%, por razones económicas (ver cuadro 8). Si bien estos son losmotivos demayor peso en el inmigrantepararesidir en la ciudad, también se puede suponer queel inmigrante con estatus deresidentelegal, no sólo tienela seguridad de permanecer en el país, sino que, además, puedecruzar la frontera con regularidad y conservar las relaciones con familiares y amigos del otro lado de la frontera. 
CUADRO 8. Motivos delosinmigrantes para residir en Caléxico, California.

\begin{tabular}{|c|c|c|c|c|c|c|}
\hline \multirow[t]{2}{*}{ Motivos } & \multicolumn{2}{|c|}{ Hombres } & \multicolumn{2}{|c|}{ Mujeres } & \multicolumn{2}{|c|}{ Total } \\
\hline & Abs. & $\%$ & Abs. & $\%$ & Abs. & $\%$ \\
\hline Esfrontera & 54 & 31.2 & 53 & 22.6 & 107 & 26.3 \\
\hline $\mathrm{R}$ & & 50.5 & & 49.5 & & \\
\hline $\mathrm{C}$ & & & & & & \\
\hline Familiares & 46 & 26.6 & 71 & 30.3117 & 28.7 & \\
\hline $\mathrm{R}$ & & 39.3 & & 60.7 & & \\
\hline C & & & & & & \\
\hline Mástranquilo & 9 & 5.2 & 18 & 7.7 & 27 & 6.6 \\
\hline $\mathrm{R}$ & & 33.3 & & 66.7 & & \\
\hline C & & & & & & \\
\hline Conocemejor & 4 & & 7 & & 11 & 2.7 \\
\hline $\mathrm{R}$ & & 36.4 & & 63.6 & & \\
\hline $\mathrm{C}$ & & 2.3 & & 3.0 & & \\
\hline Económicos & 33 & & 40 & & 73 & 17.9 \\
\hline $\mathrm{R}$ & & 45.2 & & 54.8 & & \\
\hline $\mathrm{C}$ & & 19.1 & & 17.1 & & \\
\hline Compró casa & 6 & & 14 & & 20 & 4.9 \\
\hline $\mathrm{R}$ & & 30.0 & & 70.0 & & \\
\hline $\mathrm{C}$ & & 3.5 & & 6.0 & & \\
\hline Mejor ciudad & 15 & & 21 & & 36 & 8.8 \\
\hline $\mathrm{R}$ & & 41.7 & & 58.3 & & \\
\hline $\mathrm{C}$ & & 8.7 & & 9.0 & & \\
\hline Motivos personales & 5 & & 4 & & 9 & 2.2 \\
\hline $\mathrm{R}$ & & 55.6 & & 44.4 & & \\
\hline $\mathrm{C}$ & & 2.9 & & 1.7 & & \\
\hline No respondió & 1 & & 6 & & 7 & 1.7 \\
\hline $\mathrm{R}$ & & 14.3 & & 85.7 & & \\
\hline C & & 0.6 & & 0.6 & & \\
\hline Totales & 173 & 42.5 & 234 & 57.5 & 407 & 100.0 \\
\hline
\end{tabular}

Fuente: Encuesta del proyecto "Mexicanos residentes legales en Caléxico, Ca.", IIS-UABC-SDSU, 1995.

$\mathrm{R}=$ porcentajederenglón.

$\mathrm{C}=$ porcentaje decolumna. 
CUADRO 9. Condición de los inmigrantes a partir de las expectativas que tenían al inmigar a Caléxico, California.

\begin{tabular}{|c|c|c|c|c|c|c|}
\hline \multirow[t]{2}{*}{ Espectativas } & \multicolumn{2}{|c|}{ Hombres } & \multicolumn{2}{|c|}{ Mujeres } & \multicolumn{2}{|c|}{ Total } \\
\hline & Abs. & $\%$ & Abs. & $\%$ & Abs. & $\%$ \\
\hline Sí, tienen lo suficiente & 11 & & 22 & & 33 & 8.1 \\
\hline $\mathrm{R}$ & & 33.3 & & 66.7 & & \\
\hline C & & 6.4 & & 9.4 & & \\
\hline Sí, viven mejor & 35 & & 38 & & 73 & 18.0 \\
\hline $\mathrm{R}$ & & 47.9 & & 52.1 & & \\
\hline C & & 20.2 & & 16.2 & & \\
\hline Sí, mejor sueldo & 16 & & 10 & & 26 & 6.4 \\
\hline $\mathrm{R}$ & & 61.5 & & 38.5 & & \\
\hline C & & 9.2 & & 4.3 & & \\
\hline Sí, más libertad & 1 & & 4 & & 5 & 1.2 \\
\hline $\mathrm{R}$ & & 20.0 & & 80.0 & & \\
\hline C & & 0.6 & & 1.7 & & \\
\hline Sí, mejores beneficios & 34 & & 60 & & 94 & 22.9 \\
\hline $\mathrm{R}$ & & 36.2 & & 63.8 & & \\
\hline C & & 19.7 & & 25.6 & & \\
\hline Sí, motivos económicos & 43 & & 44 & & 87 & 21.4 \\
\hline $\mathrm{R}$ & & 49.4 & & 50.6 & & \\
\hline C & & 24.9 & & 18.8 & & \\
\hline No, viven igual & 10 & & 16 & & 26 & 6.4 \\
\hline $\mathrm{R}$ & & 38.5 & & 61.5 & & \\
\hline C & & 5.8 & & 6.8 & & \\
\hline Norespondieron & 17 & & 29 & & 46 & 11.3 \\
\hline $\mathrm{R}$ & & 37.0 & & 63.0 & & \\
\hline C & & 9.8 & & 12.4 & & \\
\hline No, motivos económicos & s 6 & & 9 & & 15 & 3.7 \\
\hline $\mathrm{R}$ & & 40.0 & & 60.0 & & \\
\hline C & & 3.5 & & 3.8 & & \\
\hline No, tenían casa & & & 2 & & 2 & 5 \\
\hline $\mathrm{R}$ & & & & 100.0 & & \\
\hline C & & & & 0.9 & & \\
\hline Total & 173 & 42.5 & 234 & 57.5 & 407 & 100.0 \\
\hline
\end{tabular}

Fuente: Encuesta del proyecto “M exicanos residentes legales en Caléxico, Ca.",IIS-UABC-SDSU, 1995.

$\mathrm{R}=$ Porcentaje de renglón. $\mathrm{C}=$ Porcentaje de columna. 
El inmigrante a su llegada trae consigo un gran número de expectativas, entre las que destaca la de encontrar un trabajo mejor remunerado, y así lograr un mejor nivel de vida para él y su familia. De los inmigrantes entrevistados, $78 \%$ declaró haber logrado sus expectativas; de ellos, más del $22 \%$ dijo tener mayores beneficios (trabajo, vivienda, servicios desalud) quel os quetenía en México; $21.4 \%$ se encuentran en mejores condiciones económicas, y $18 \%$ respondió que vive mejor (ver cuadro 9).

Sin embargo, $10.6 \%$ no han logrado los objetivos que se habían propuesto; $6.4 \%$ vive en las mismas condiciones que en México; $3.7 \%$ respondió queen cuanto a lo económico no era lo queesperaban, y $0.5 \%$ respondió que estaba mejor en su país, pues al lá tenían casa y aquí no.

Por otra parte, del total de los inmigrantes entrevistados, $85.7 \%$ declaró queal inmigrar había encontrado trabajo. Deesegrupo, $47.4 \%$ encontró trabajo en la agricultura, $21.1 \%$ en el área de servicios, $8.4 \%$ en la construcción, y $8.1 \%$ en servicios comunales; los que no respondieron representan el $0.7 \%$. El $14.3 \%$ restante del total de entrevistados son mujeres quenunca han trabajado, por lo que puede aducirse que inmigraron a fin de reunirse con la familia o por matrimonio, quees común entrehabitantes de poblaciones fronterizas.

Por lo anterior, puedeconsiderarsequela ciudad deCaléxico sigue siendo un punto de atracción para que el inmigrante se integre al mercado laboral y a la comunidad receptora de la región, lo que ha favorecido ala mayoría delos inmigrantes mexicanos para quepuedan lograr sus expectativas de bienestar económico y social, propósito principal por el cual inmigraron.

\section{MIGRACIÓN DE RETORNO: CONTACTO CON EL PAÍSDE ORIGEN}

El proceso migratorio se constituye por tres momentos: los primeros son la partida del lugar deorigen y la ll egada al lugar de destino delos migrantes; el tercer momento quese contempla en el círculo migratorio es la migración de retorno, parte en la que el migrante manifiesta el interés y atracción que siente por su país, aun cuando no considere la posibilidad de volver definitivamente, sino que se da a partir de las relaciones sociales, económicas y políticas queel inmigrantemantiene 
a través de los contactos y lazos que construyen la comunicación entre él y su país deorigen (Kenny, et al.,1979:15). Esta partedel movimiento migratorio es más común entre los migrantes indocumentadosquevan y vienen; sin embargo, entre los inmigrantes legal es que residen de manera permanente, sigue existiendo en ellos el deseo de volver, tal vez no demanera definitiva, pero sí eventual mente. Los resultados de la encuesta indican quedel total delosinmigrantes entrevistados, 87.2\% no tiene contemplado regresar de manera definitiva a México; sólo al $12.8 \%$ le gustaría volver, y de este porcentaje, 7.9\% respondió que "regresaría a México porque es su patria”, "por la familia”, "cuando estén viejos" y "por la forma (valores) devida quesetieneen México". El 4.3\% delos quecontemplan volver, dijo que "regresaría a trabajar", porque "la vida en Estados Unidoses muy cara", o lo harían "si tuvieran problemas legales". El 0.5\% de los entrevistados no respondió.

Volver deforma definitiva sería difícil para la mayoría, pues como se mencionó, muchos tienen resuel tos los problemas por los cuales tuvieron que dejar su país, aunque en general el inmigranteno pierde el contacto con su lugar deorigen, ya que mantienelos vínculos sociales establecidos a través de visitas y estancias querealizan frecuentemente. Por ejemplo, más del $50 \%$ de los entrevistados cruza la frontera una vez a la semana a la ciudad de Mexicali, Baja California; $26 \%$ una vez al mes; $12.3 \%$ todos los días, y sólo el 3.2\% respondió que no cruza la frontera (ver cuadro 10).

Lo quemotivó amás delamitad deestegrupo deinmigrantes (56.1\%) a cruzar la frontera, es ir a visitar a sus familiares; $24.4 \%$ lo hace para real izar compras (productos deabarrotes, sobretodo cuando la paridad del peso-dólar es significativa); $13.5 \%$ va a visitar a los amigos, y sólo el $1.0 \%$ cruza al lado mexicano para trabajar. Aquí es convenienterecordar que de la población en estudio, $47.7 \%$ son nacidos en Baja California, por lo quelas relaciones familiares y sociales son másestrechas, y también sedebetener presenteque la distancia entrelas ciudades de M exicali y Caléxico es casi nula: sólo las separa una malla metálica.

Otra forma de mantener el contacto con su país son los viajes que real izan a M éxico: más del $40 \%$ ha viajado en varias ocasiones a visitar a susfamiliares; $13.3 \%$ en plan devacaciones, y $1.7 \%$ por otrosmotivos. El 43.2\% de los entrevistados no ha viajado al interior del país. 
CUADRO 10. Frecuencia de cruces fronterizos a la ciudad de Mexicali, B.C. delosinmigrantesmexicanos residentesen Caléxico, California.

\begin{tabular}{|c|c|c|c|c|c|c|}
\hline \multirow{2}{*}{$\begin{array}{l}\text { Frecuencia de cruce } \\
\text { fronterizos }\end{array}$} & \multicolumn{2}{|c|}{ Hombres } & \multicolumn{2}{|c|}{ Mujeres } & \multicolumn{2}{|c|}{ Total } \\
\hline & Abs. & $\%$ & Abs. & $\%$ & Abs. & $\%$ \\
\hline Todos losdías & 34 & & 16 & & 50 & 12.3 \\
\hline $\mathrm{R}$ & & 68.0 & & 32.0 & & \\
\hline C & & 48.6 & & 51.7 & & \\
\hline Una vez a la semana & 84 & & 121 & & 205 & 50.4 \\
\hline $\mathrm{R}$ & & 41.6 & & 59.0 & & \\
\hline $\mathrm{C}$ & & 48.6 & & 51.7 & & \\
\hline Una vez al mes & 38 & & 68 & & 106 & 26.0 \\
\hline $\mathrm{R}$ & & 35.8 & & 64.2 & & \\
\hline C & & 22.0 & & 29.1 & & \\
\hline Nunca & 6 & & 7 & & 13 & 3.2 \\
\hline $\mathrm{R}$ & & 46.2 & & 53.8 & & \\
\hline C & & 3.5 & & 3.0 & & \\
\hline Otros & 11 & & 22 & & 33 & 8.1 \\
\hline $\mathrm{R}$ & & 33.3 & & 66.7 & & \\
\hline C & & 6.4 & & 9.4 & & \\
\hline Total & 173 & 42.5 & 234 & 57.5 & 407 & 100.0 \\
\hline
\end{tabular}

Fuente: Encuesta del proyecto "Mexicanos residentes legales en Caléxico, Ca.", IIS-UABC-SDSU, 1995.

$\mathrm{R}=$ Porcentaje de renglón. $\mathrm{C}=$ Porcentaje de columna.

Delosquesí realizan viajesal interior deM éxico, 37.8\%, permanecen al rededor de dos semanas, $12.5 \%$ se queda un mes, y $6.4 \%$ indicó que sus estancias son variadas.

Otro aspecto dela reemigración esla participación queel inmigrante puede tener en los acontecimientos de la vida política de su país. El vivir en el extranjero no es limitante para que los mexicanos puedan participar en la vida política de su país de origen, por lo que en el momento de la encuesta se tomó en consideración lo que establecela Constitución política delos Estados Unidos Mexicanos, queen el Título Primero, capítulo IV, relativo a los derechos de los ciudadanos 
mexicanos, menciona en su artículo 35, fracciones I y II: “son prerrogativas del ciudadano; el votar en las elecciones populares y poder ser votado para cual quier cargo deelección popular" (C onstitución política de los Estados U nidos M exicanos, 1995:58).

CUADRO 11. Viajes al interior de México. Inmigrantes mexicanos legales en Caléxico, California.

\begin{tabular}{|c|c|c|c|c|c|c|}
\hline \multirow{2}{*}{ Motivos } & \multicolumn{2}{|c|}{ Hombres } & \multicolumn{2}{|c|}{ Mujeres } & \multicolumn{2}{|c|}{ Total } \\
\hline & Abs. & $\%$ & Abs. & $\%$ & Abs. & $\%$ \\
\hline Vacaciones & 27 & & 27 & & 54 & 13.3 \\
\hline $\mathrm{R}$ & & 50.0 & & 50.0 & & \\
\hline C & & 15.6 & & 11.5 & & \\
\hline Visitar a familiares & 70 & & 100 & & 170 & 41.8 \\
\hline $\mathrm{R}$ & & 41.2 & & 58.8 & & \\
\hline C & & 40.5 & & 42.7 & & \\
\hline Fiestas patronales & & & 3 & & 3 & 0.7 \\
\hline $\mathrm{R}$ & & & & 100.0 & & \\
\hline C & & & & 1.3 & & \\
\hline Otros & 2 & & 2 & & 4 & 1.0 \\
\hline $\mathrm{R}$ & & 50.0 & & 50.0 & & \\
\hline $\mathrm{C}$ & & 1.2 & & 0.9 & & \\
\hline No han viajado al & & & & & & \\
\hline interior deMéxico & 74 & & 102 & & 176 & 43.2 \\
\hline $\mathrm{R}$ & & 42.0 & & 58.0 & & \\
\hline $\mathrm{C}$ & & 2.8 & & 43.6 & & \\
\hline Total & 173 & 42.5 & 234 & 57.5 & 407 & 100.0 \\
\hline
\end{tabular}

Fuente: Encuesta del proyecto "M exicanos residentes legales en Caléxico, Ca.", IIS-UABC-SDSU, 1995.

$\mathrm{R}=$ Porcentaje de renglón. $\mathrm{C}=$ Porcentaje de columna. 
CUADRO 12. Participación política en M éxico delos inmigrantes mexicanos residentes legales en Caléxico, California.

\begin{tabular}{|c|c|c|c|c|c|c|}
\hline \multirow{2}{*}{$\begin{array}{l}\text { Participación } \\
\text { política }\end{array}$} & \multicolumn{2}{|c|}{ Hombres } & \multicolumn{2}{|c|}{ Mujeres } & \multicolumn{2}{|c|}{ Total } \\
\hline & Abs. & $\%$ & Abs. & $\%$ & Abs. & $\%$ \\
\hline \multicolumn{7}{|l|}{ No leinteresa } \\
\hline $\mathrm{R}$ & 89 & 45.4 & 107 & 54.6 & 196 & 54.0 \\
\hline C & & 59.3 & & 50.2 & & \\
\hline \multicolumn{7}{|l|}{ No tienederecho } \\
\hline $\mathrm{R}$ & 46 & 38.3 & 74 & 61.7 & 120 & 33.1 \\
\hline C & & 30.7 & & 34.7 & & \\
\hline \multicolumn{7}{|l|}{ No tiene credencial } \\
\hline $\mathrm{R}$ & 10 & 28.6 & 25 & 71.4 & 35 & 9.6 \\
\hline C & & 6.7 & & 11.7 & & \\
\hline \multicolumn{7}{|l|}{ No sabe } \\
\hline $\mathrm{R}$ & 5 & 41.7 & 7 & 58.3 & 12 & 3.3 \\
\hline C & & 3.3 & & 3.3 & & \\
\hline Total & 150 & 41.3 & 213 & 58.7 & 363 & 100.0 \\
\hline
\end{tabular}

Fuente: Encuesta del proyecto "Mexicanos residentes legales en Caléxico, Ca.", IIS-UABC-SDSU, 1995.

$\mathrm{R}=$ Porcentaje de renglón. $\mathrm{C}=$ Porcentaje de columna.

A partir delo establecido en el artículo citado y por las características de este grupo de inmigrantes mexicanos que no son ciudadanos estadounidenses pero sí residentes legales y deuna ciudad fronteriza, seles preguntó si ejercían el derecho devotar en su país, a lo que $86.2 \%$ manifestó que no vota en México. Al cuestionarlos acerca del por qué no ejercen ese derecho, 54.0\% manifestó que no tienen interés; 33.1\% dijo no tener derecho; $9.6 \%$ respondió que no lo hace por no tener credencial para votar, y 3.3\% no sabesi puedevotar en México porque viveen otro país. Sólo $10.8 \%$ de los inmigrantes sí ejercen estederecho y votan en las elecciones para presidentedela república. Sin embargo, $60.4 \%$ delos inmigrantes saben quepor encontrarseresidiendo en otro país no han perdido sus derechos como ciudadanos mexicanos; $27.3 \%$ de ellos ignora si perdió los derechos, y $12.3 \%$ afirma que por vivir en el extranjero no tiene ningún derecho en su país. 
Por lo anterior, puede decirsequeel inmigranteno pierde contacto con su país, ya que prevalece en ellos uno de los valores culturales más fuerteentre los mexicanos, quees la relación y vínculos familiares.

En cuanto al aspecto político, se puede observar queen la mayoría delos inmigrantes existe poco interés de participar, lo quesin duda se debeal hecho dequeno tienen contemplado volver definitivamentea su país, aun cuando la mayoría tieneconocimiento dequepor vivir en el extranjero no han perdido sus derechos como ciudadanos mexicanos.

\section{CONSIDERACIONESFINALES}

A lo largo dela historia, la inmigración demexicanosen Estados Unidos se ha debido a las fuertes diferencias económicas que existen entre ambos países, lo que ha dado como resultado quela migración refleje características particulares al ser considerada solamente como un desplazamiento defuerza detrabajo. Pero sedebereconocer quedicho movimiento está cargado de peculiaridades en cuanto al aspecto social del migrante, y queesteproceso sól o se ha explicado como respuesta a las necesidades estructural es de ambos países: uno de ellos, Estados Unidos abre sus puertas cuando hay necesidad de mano de obra y las cierra cuando dichas necesidades son cubiertas (Galarza, 1977:4), y México, históricamente, se ha convertido en el abastecedor de fuerza de trabajo, lo que en gran medida ha servido como una válvula de escape para mantener en cierto grado su estabilidad social.

El presente trabajo ha pretendido mostrar que en el proceso migratorio intervienen diferentes variables, y quedesdela perspectiva del ciclo migratorio que aquí se plantea, se puede concluir quesi bien existen al gunas deellas queson determinantes para que los inmigrantes tomen la decisión de migrar - como lo es mejorar las condiciones de vida-, también se puede deducir que el migrante, antes de tomar la decisión deemigrar, hace una eval uación dela realidad: por una parte, ve el desempleo y la incapacidad del sistema mexicano para generar fuentes de trabajo y ofrecer mejores salarios; y por la otra, ve la diferencia en cuanto a las oportunidades deempleo y lossal arios mejor remunerados que obtiene al inmigar a Estados Unidos. 
Al señalar las causas queintervienen en la fase dela emigración, se tiene como resultado que la población de inmigrantes mexicanos en Estados Unidos tiene actualmente características diferentes, pues si bien al principio estaba constituida por trabajadores rurales y eran generalmente los más pobres los que emi graban (Gamio, 1930:42), en la actualidad las personas emigran aun cuando cuentan con empleo en su país, como es el caso dela mayoría deestegrupo deinformantes.

En este contexto de búsqueda de mejores condiciones de vida, el factor quesurge como un mecanismo quefacilita estemovimiento son las redes sociales queseconstruyen a través delas relaciones familiares y de amistad, las cuales son de gran apoyo para queel inmigrante se integre a la sociedad receptora. Otro papel que juegan estas redes sociales es la deinformar a losfamiliares directos cómo pueden inmigrar de manera legal a partir de lo que establecen las leyes migratorias en Estados Unidos, a las cuales recurren la mayoría de los inmigrantes establecidos debido a los derechos que han adquirido.

Por ello, en este caso específico se puede decir que al emigrar, la mayoría deestegrupo deinmigrantes establecido y con residencialegal, ha logrado sus objetivos deobtener mejores condiciones devida y reunir a la familia; sin embargo, añoran olores y sabores, extrañan a familiares y amigos, por lo que no pierden contacto con su país, al que regresan devez en cuando sól o de visita, pues no tienen contemplado volver de forma definitiva. Así, puede decirse que los inmigrantes mexicanos legales en Estados Unidos, son parte de la población que México ha perdido como resultado de las particularidades y factores que intervienen en el proceso dela migración internacional. 


\section{BIBLIOGRAFÍA}

Alba, Francisco (1986). “Éxodo silencioso: La emigración detrabajadores mexicanos a Estados Unidos", M igración y desarrollo, Consejo Latinoamericano de Ciencias Sociales, El Colegio de México, México, D.F.

Bustamante, Jorge A. y Gerónimo Martínez (1980). “Migración indocumentada: la política de las perspectivas y la estructura de las real idades", Curso intensivo sobremigración indocumentada de México a Estados Unidos, (mimeo), 20 de octubre al 5 de noviembre de 1980, El Colegio de México, México, D.F.

U.S. Bureau of the Census. Census of Population, 1990. Washington, D. C. Constitución política delos Estados U nidos M exicanos (1995). Coordinador: Javier Moreno Padilla, Ed. Trillas, México, D.F.

Comisión sobre el futuro de las relaciones México-Estados Unidos (1988). El desafío dela interdependencia: M éxico- Estados U nidos. FCE, México, D.F.

Estrella Val enzuela, Gabriel (1982). “El origen dela región delos valles de Mexicali e Imperial, desde la perspectiva de las relaciones sociales", Cuadernos de ciencias sociales, núm. 1, Instituto de Investigaciones Sociales, Universidad Autónoma de Baja California, M exicali, Baja California.

Galarza, Ernesto (1977). Farm W orkers and A gri-business in California. 1947-1960. University of N otre Dame Press, Londres.

Gamio, Manuel (1930). M exican Immigration to theU nited States. A study of $\mathrm{H}$ uman $\mathrm{M}$ igration and A djustment, Chicago, Illinois.

García y Griego, Manuel y Mónica Verea Campos (1988). M éxico y Estados U nidos. Frentea la migración indocu mentada, editada por la Coordinación de Humanidades de la UNAM y el grupo editorial Miguel Ángel Porrúa, México, D.F.

INEGI. XI Censo general de población y vivienda, 1990. Resultados definitivos. Tabulados básicos. Baja Cal ifornia, INEGI, Ags.

Kenny, Michael, Virginia García, Carmen Icazuriaga, Clara Elena Suárez y Gloria Artís (1979). Inmigrantes y refugiados españoles en M éxico (siglo XX), Ediciones de la Casa Chata, México, D.F. 
López Castro, Gustavo (1986). "Migración temporal a Estados Unidos en una comunidad rural mexicana", en:...Sefuea volver, Seminario sobremigracionestemporalesen A mérica Latina. PISPAL/ CIUDAD/ CENEP. México.

Massey, Douglas, Rafael A larcón, Jorge Durand y Humberto González (1991). Los ausentes. Consejo Nacional parala Culturay las A rtesEd. Alianza. México, D.F. 